\title{
Instructor's Rating of Driver's Performance during an Anti-Lock Braking Exercise on a Closed-Road Course
}

\author{
Lauren Mims ${ }^{1, *}$, Johnell O. Brooks ${ }^{1}$, Timothy M. Jenkins ${ }^{1}$, Casey Jenkins ${ }^{1}$, Joseph Neczek ${ }^{2}$, Donnie Isley ${ }^{3}$, \\ Allison Bormann ${ }^{3}$, Laura Hayes ${ }^{3}$ and Daniel Gubitosa ${ }^{3}$ \\ 1 Department of Automotive Engineering, Clemson University, Greenville, SC 29607, USA; \\ jobrook@clemson.edu (J.O.B.); tmjenki@g.clemson.edu (T.M.J.); caseyj@clemson.edu (C.J.) \\ 2 Edward Hines Jr. VA Hospital, Hines, IL 60141, USA; Joseph.Neczek@va.gov \\ 3 BMW Performance Center, Greer, SC 29651, USA; Donnie.Isley@bmwmcext.com (D.I.); \\ allisonbormann@gmail.com (A.B.); laurahayes21@gmail.com (L.H.); Daniel.gubitosa@bmwna.com (D.G.) \\ * Correspondence: Imims@g.clemson.edu; Tel.: +1-864-283-7272
}

check for

updates

Citation: Mims, L.; Brooks, J.O.; Jenkins, T.M.; Jenkins, C.; Neczek, J.; Isley, D.; Bormann, A.; Hayes, L.; Gubitosa, D. Instructor's Rating of Driver's Performance during an Anti-Lock Braking Exercise on a Closed-Road Course. Safety 2021, 7, 62. https://doi.org/10.3390/ safety7030062

Academic Editor: Raphael Grzebieta

Received: 13 April 2021

Accepted: 29 August 2021

Published: 3 September 2021

Publisher's Note: MDPI stays neutral with regard to jurisdictional claims in published maps and institutional affiliations.

Copyright: (c) 2021 by the authors. Licensee MDPI, Basel, Switzerland. This article is an open access article distributed under the terms and conditions of the Creative Commons Attribution (CC BY) license (https:/ / creativecommons.org/licenses/by/ $4.0 /)$.

\begin{abstract}
Rear-end crashes are a common crash scenario, which contribute to many traffic related injuries and fatalities. A performance driving center offers adult car control classes focused on defensive driving skills, which include both classroom and behind-the-wheel instruction on a closedroad course. One focus of the class is activation of the anti-lock braking system (ABS), which was designed to help drivers during emergency braking situations. In the classroom, participants learn what ABS is as well as how and when it functions. On the closed-road course, participants learn how to activate ABS and how the system feels when it is activated. The goal of this study was to understand how knowledge of and experience with ABS prior to the class relates to a driver's ability to activate ABS. The participants' ability to activate ABS was evaluated by the driving instructor using a behaviorally anchored rating scale. Participants completed a survey before and after the class to gain knowledge of and experience with ABS. The results of the study showed that participants who previously knew what ABS felt like or had prior practice/training activating ABS performed significantly better activating ABS than those who simply knew what ABS means or had previously experienced ABS activation during their first of multiple attempts.
\end{abstract}

Keywords: adult drivers; emergency braking; post-license training; braking performance; anti-lock braking system training; closed-road track

\section{Introduction}

Traffic crashes are one of the primary causes of injuries and fatalities around the world [1]. Most of today's crashes in the US can be attributed to driver error (94\%), primarily consisting of recognition (41\%), decision (33\%) and performance errors (11\%) [2]. As technology has advanced over time, the capabilities of vehicles have evolved over time. This shift has been observed in braking technology, where brakes not only serve to stop the vehicle, but also to assist the driver during emergency braking situations.

\subsection{Background}

\subsubsection{Anti-Lock Braking System Overview}

The anti-lock braking system (ABS) was developed to assist drivers during panic braking by preventing skidding or loss of control caused by locked wheels or a wheel that cannot rotate and is sliding [3]. When the wheels are locked, the driver does not retain control of the steering and thus cannot steer the vehicle even when turning the steering wheel. ABS was introduced on passenger vehicles in the 1980s with the hope of reducing the number of crashes [4]. Vehicles with conventional (pre-ABS) brakes required the driver to "pump" the brake pedal, or to rapidly press and release the brake pedal, during an emergency braking situation. Drivers often had a difficult time pumping the pedal at the 
correct frequency, which if performed incorrectly can cause the vehicle's wheels to lock and the driver to lose control of steering and braking of the vehicle. ABS automated this action for the driver by holding and releasing the brakes, which optimizes the brake pressure and prevents the wheels from locking and skidding. Since ABS quickly holds and releases the brake pressure, the driver experiences a vibration or "thumping" in the pedal when ABS is engaged. A benefit of ABS activation is the driver remains in control of the braking and can steer the vehicle [4].

The National Highway Traffic Safety Administration (NHTSA) investigated crash records to see if there was a benefit of ABS. NHTSA's initial report showed that even though there was a reduction in fatal multi-vehicle crashes on wet roads, there was a significant increase in the number of fatal single vehicle run-off road crashes [4]. As a result of these findings, ABS was not required as standard safety equipment and NHTSA launched the Light Vehicle ABS Research Program to investigate why ABS was not effective in reducing all types of crashes [5]. The Light Vehicle ABS Research Program found that drivers did not understand the purpose of ABS, did not know when ABS was functioning, or if their vehicle was even equipped with ABS. Another major finding was that when ABS was activated, the vibration (thumping) feedback from the pedal was not understood by some drivers. This misunderstanding of the pedal vibration feedback could lead to dangerous reactions from drivers such as releasing the brake pedal [6]. Though ABS began appearing on vehicles in the 1980s, it first appeared in the luxury vehicle segment before trickling down into the higher volume economy cars in the early 1990s. This initial evaluation of ABS examined traffic crashes between 1989 and 1993, which consisted of vehicles up to model year 1992 [4]. NHTSA conducted a second, multi-year observational study on ABS, spanning from 1995 to 2007 with a larger pool of vehicles equipped with ABS, where a similar trend of a decrease in multi-vehicle crashes on wet roads and an increase in run-off the road crashes was observed [7].

In 2012, the functionality of ABS became standard safety equipment on all new passenger vehicles in the US as part of the Electronic Stability Control (ESC) system [8], due to ESC's reduction in crashes, especially those involving light trucks and SUVs [9-11]. ESC was created to help prevent loss of traction resulting in rotation caused by steering input that ABS cannot eliminate. Like ABS, ESC automatically makes braking adjustments at the individual wheels, but ESC also reduces engine output by comparing inputs from the driver (steering wheel angle) with the vehicle's motion (speed of the individual wheel, yaw rate and lateral acceleration) [12]. ESC has been estimated to reduce fatal rollovers by approximately $59.5 \%$ in cars and $74.0 \%$ in light trucks and SUVs as well as reducing other fatal single vehicle crashes by approximately $31.3 \%$ in cars and $45.5 \%$ in light trucks and SUVs [9].

Though there have been improvements in vehicle technology and safety systems from an engineering perspective, a disproportionately high number of rear-end crashes still exist. In 2015, there were over two million rear-end collisions in the US, which account for $33.4 \%$ of all crashes, $6.8 \%$ of all fatal crashes, $32.4 \%$ of all injury causing crashes and $33.9 \%$ of crashes that resulted in property damage only [13]. In 2017, 39\% of all fatal crashes in the US involved collisions with other vehicles, where $7.2 \%$ of all fatal crashes were rear-end crashes [14]. Even though ABS is required on vehicles and there is a high number of rear-end crashes in the US, ABS activation is not required during the license test to obtain a driver's license in the US (e.g., [15-18]. Some states may ask drivers to stop quickly (e.g., $[15,18])$, but there is no specification for an ABS stop.

Few researchers have investigated the effects of ABS training on braking performance. Mollenhauer, Dingus, Carney, Hankey and Jahns [19], investigated a low-cost training method involving drivers who had no previous experience with ABS. The drivers were divided into two groups, where one group of drivers was shown a pamphlet explaining the correct brake activation technique and the other was not. All participants drove on an icy track where they were asked to stop as quickly as possible. The results of the study showed that the drivers that reviewed the pamphlet used the correct activation technique 
and stopped an average of $35 \mathrm{ft}$ sooner when traveling in a straight line compared to participants that did not review the pamphlet. The study included curved and surprise braking events, but there were no differences observed between the groups on either. Petersen, Barrett, and Morrison [20] investigated brake performance as a result of a twoday post-license training program. One group of drivers was enrolled in the program and the other group, a control group, received no training. The group enrolled in the program received ABS training using a two-phase braking technique, which was taught because it could be used in vehicles with and without ABS. The two-phase braking technique required the driver to first depress the pedal quickly near the maximum travel of the pedal, then, for the remaining distance of pedal travel, the driver applies pressure steadily until the pedal is fully depressed. The results showed that the group enrolled in the program did not rely on ABS as much as the control group to stop; therefore, the program group had smoother braking profiles. As a result, the program group took a full car length distance more to stop than the control group.

In order to provide ABS training and other defensive driving skills in the hopes of reducing driver error in controlled environments, post-license driving programs have emerged in the US. The programs vary drastically, from some that cater to new drivers with little experience, take place in parking lots, and are taught by volunteers who are driving enthusiasts to courses that cater to performance driving on closed road courses for individuals with racing experience. Regardless of the platform, the common goal between all programs is the desire to improve drivers' ability to control the vehicle using behind-the-wheel instruction in a controlled environment. Many of these programs include ABS exercises, with the goal of giving students the opportunity to activate ABS (e.g., https: //www.guardyourlifechallenge.com/, https:/ / putonthebrakes.org/, http:/ / raceschool. $\mathrm{com} /$, https: / /bondurant.com/ (accessed on 18 November 2020)). Even though multiple programs are available, there is limited data on the impact of these courses on drivers' knowledge of ABS as well as their ability to activate ABS.

\subsubsection{Performance Driving Center Classes}

The performance center collaborated with the research team to study driver ABS skills in a facility housing classroom and a closed-road course (https: / / bmwperformancecenter. com, (accessed on 18 November 2020)). The center offers multiple classes for all driver's ages and skill levels, ranging from novice to advanced drivers. Some of the most popular courses are the teen and adult car control classes, which provide both classroom and behindthe-wheel instruction focused on defensive driving skills using a variety of exercises on the closed-road course. These classes are either one or two full days. Drivers enrolled in these classes gain knowledge on proper driving behaviors, such as where and how far ahead to look when driving, optimal seating, as well as proper feet and hand positioning. Other goals of these classes are an improved understanding of vehicle safety systems like ABS and ESC, as well as experience performing emergency maneuvers including skid recovery and emergency lane changes. For additional details about the class, please see Mims et al. [21].

One key aspect of both the one and two-day classes is gaining hands-on experience using ABS. During the classroom instruction, the instructors provide an explanation of how ABS works, how to activate ABS and what drivers will experience while on the closed-road course during the ABS exercise. Drivers are instructed to slam on the brake pedal as hard as possible and hold the pedal until the vehicle comes to a complete stop. The instructors explain that due to the rapid engagement and release of the ABS system the drivers should expect to feel a vibration or "thumping" in the brake pedal. After the classroom portion, the participants move to the closed-road course for behind-the-wheel instruction (see Figure 1). There are typically a maximum of 16 individuals enrolled in a class. At the beginning of the class participants are divided into two groups, with a maximum of four vehicles per group. With up to two people per vehicle, the individuals are assigned to either drive first or be the passenger first. 


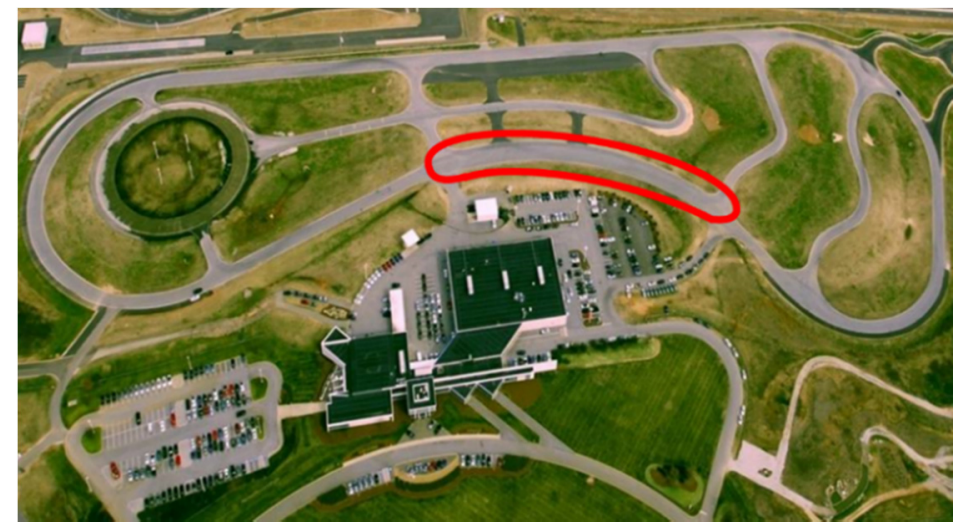

Figure 1. Aerial view of the closed-road course (ABS exercise area in red).

Drivers slowly drive through the course and are instructed to brake at a designated set of cones and come to a complete stop before receiving feedback from the instructor. Participants are reminded to stomp on the brake pedal as quickly as possible and hold it all the way down until the vehicle came to a complete stop. As part of the instruction while driving through the course, the class participants stop near the cones and estimate the distance to stop at multiple speeds. The instructor then shows the actual distance needed to stop to help gain an understanding of how the distance needed to stop changes at different vehicle speeds.

Next, the drivers are instructed to accelerate to a given speed then activate ABS when reaching a designated set of cones (see Figure 2). Drivers begin the ABS exercise driving 30-35 miles per hour and with each run continuously increase their speed up to 55-60 miles per hour (mph). The area of the closed-road course where the exercise occurs has a turn near the end (Figure 2). As the speed of each practice run increases, the distance it takes the driver to stop dramatically increases. Once the driver is traveling around $50 \mathrm{mph}$, the drivers must steer while they are braking. Each driver typically has six to seven runs, with the speed increasing on each run to a maximum of $60 \mathrm{mph}$. After each run, the drivers receive feedback from the instructor standing on the side of the course via a two-way radio (the driver's radio is located in the driver's door storage area). Once the first group of drivers completes the exercise, the drivers and passengers switch seating positions, and the exercise is repeated.
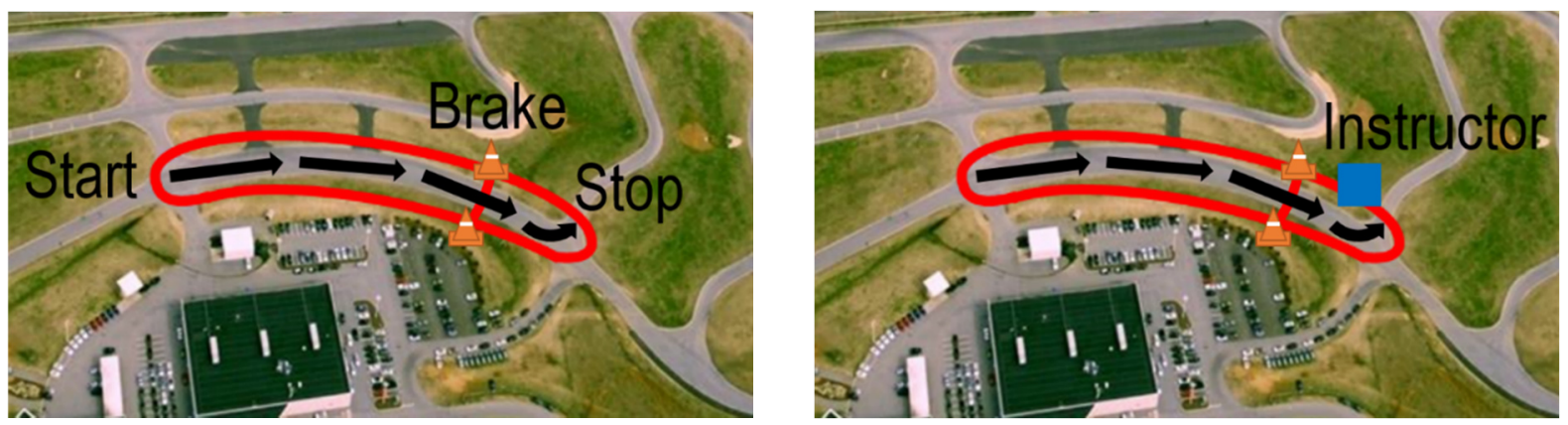

Figure 2. Map of the ABS exercise.

A previous study investigated the drivers' views of the class, where a pre and posttest survey was conducted with several one-day teen and adult classes [21]. The results suggested that both the teens $(N=80)$ and adults $(N=177)$ identified ABS braking as one of the most important topics taught during the class. The teens and adults reported increased competence in their ability to stomp on the brakes to activate ABS and steer while braking. On average teens and adults reported not feeling competent (average score of 3.2 for the teens and 3.6 for the adults out of 6 , where 6 was fully competent to perform without 
further training) before the class and reported feeling more competent (average score of 5.6 for the teens and 5.4 for the adults out of 6) in their ability to activate ABS directly after the class. In regard to their ability to steer and brake simultaneously, the teens and adults did not feel competent prior to the class (average score of 2.8 for the teens and 3.5 for the adults), but once again felt more competent directly after the class (average score of 5.5 for the teens and 5.3 for the adults). The adults had the opportunity to participate in a follow-up phone interview six months after the class; they reported that ABS braking was one of the most used skills on the road from the entire class and ABS braking was the most frequently used skill from the class to avoid a crash.

The results from the previous study [21], suggested that both teen and adult drivers considered the information about ABS and the experience activating ABS to be of high importance, which supports the hypothesis that many drivers did not have prior knowledge or experience with ABS. This is consistent with the observations from Mazzae, Garrott \& Snyder [6], that drivers did not understand the purpose of ABS. This study investigates drivers' understanding and ability to activate ABS based on professional driving instructors' performance ratings.

\section{Methods}

\subsection{Participants}

Participants in this study were drivers enrolled in a one-day performance driving class at a local closed-road course facility. Ninety participants were enrolled in the study. Eleven participants were dropped due to either missing instructor ratings or survey data. Of the remaining 79 participants, drivers' ages ranged from 18 to 78 years $(M=45.4, S D=14.1)$, including 61 males and 18 females. There were 12 participants between the ages of 18 to 29 , 15 participants between the ages of 30 to 39, 18 participants between the ages of 40 to 49 , 21 participants between the ages of 50 to 59,10 participants between the ages of 60 to 69 , and 3 participants between the ages of 70 to 78 . Participants received a \$25 VISA gift card in exchange for their participation.

\subsection{Survey and Rating Scale}

A pre-test survey assessed each participant's demographic information, knowledge of ABS and previous experience with ABS, see Table 1. A post-test survey consisted of questions targeted to the participants' experience during the class (Table 1).

To have the instructors quantify the participants' performance when attempting to activate ABS, a behaviorally anchored rating scale (BARS) was developed to measure performance [22]. The development of BARS relies on the involvement of subject matter experts, who provide behavior-based examples of varying levels of performance for a task. Three driving instructors that regularly lead the ABS exercise collaborated with the research team to develop this scale. The scale consists of five ratings, where a rating of 1 represents no ABS activation, 2 represents brief activation, 3 represents some activation, 4 represents activation throughout most of the stop, and 5 represents full ABS activation throughout the entire stop, see Table 2 for a detailed description of each rating which includes a description of the driver's actions as well as what the instructor would observe. 
Table 1. Pre- and post-test survey questions. Items in parentheses are requirements to participate in the study and/or examples of correct responses.

\begin{tabular}{|c|c|c|}
\hline Survey & Question & Response Option \\
\hline \multirow{15}{*}{ Pre-test } & What is your age? (Must be a minimum of 18 years old) & Open-ended \\
\hline & What is your gender? & Open-ended \\
\hline & Do you have a US driver's license? (Must have a US or international driver's license) & Yes/No \\
\hline & What does ABS stand for? (Correct response: anti-lock braking system) & Open-ended \\
\hline & $\begin{array}{l}\text { If you had to describe the purpose of ABS to someone else, what would you say? } \\
\text { (Examples of correct responses: keeping the wheels from locking up, automatically } \\
\text { pumping the pedal, retaining the ability to steer, etc.) }\end{array}$ & Open-ended \\
\hline & $\begin{array}{l}\text { What do you feel when ABS is activated? (Examples of correct responses: vibration of } \\
\text { the vehicle or brake pedal, etc.) }\end{array}$ & Open-ended \\
\hline & Have you ever used ABS? & Yes/No \\
\hline & - $\quad$ If yes, what did you experience? & Open-ended \\
\hline & - If yes, the first time this happened to you, what did you think was going on? & Open-ended \\
\hline & - $\quad$ If yes, at that moment, did you immediately know what was happening? & Yes/No \\
\hline & - $\quad$ If yes, describe the environment. & Open-ended \\
\hline & Have you ever practiced using ABS? & Yes/No/I don't know \\
\hline & Did you take driver's education when you were learning to drive? & Yes/No \\
\hline & Have you taken any additional driver's training courses (excluding driver's education)? & Yes/No \\
\hline & - $\quad$ If yes, did you get behind the wheel experience with ABS? & Yes/No \\
\hline \multirow{3}{*}{ Post-test } & What was the hardest part about the ABS exercise? & Open-ended \\
\hline & $\begin{array}{l}\text { Has today's class changed your understanding of what ABS is, how it works, or what } \\
\text { the driver feels? }\end{array}$ & Yes/No \\
\hline & - $\quad$ If yes, what do you know now that you did not know before? & Open-ended \\
\hline
\end{tabular}

Table 2. Description of each rating including what action the driver took and what the vehicle does or what the instructor sees.

\begin{tabular}{|c|c|c|c|}
\hline Rating & Level of Activation & Driver Action & Instructor Sees/What the Vehicle Does \\
\hline 1 & None & $\begin{array}{l}\text { Does not press the brake pedal hard enough to } \\
\text { lock the wheels, thus not activating ABS }\end{array}$ & $\begin{array}{l}\text { No rise or dive of the nose, wheels are } \\
\text { continuously rolling }\end{array}$ \\
\hline 2 & Brief & $\begin{array}{l}\text { Presses the brake pedal hard enough to lock } \\
\text { the wheels and activate ABS momentarily, the } \\
\text { pedal pressure is not consistent or enough to } \\
\text { sustain ABS }\end{array}$ & $\begin{array}{l}\text { The wheels momentarily lock and ABS releases the } \\
\text { wheels causing what appears to be a ratcheting } \\
\text { effect, the nose of the vehicle is pointing } \\
\text { downward briefly }\end{array}$ \\
\hline \multirow{3}{*}{3} & \multirow{3}{*}{$\begin{array}{l}\text { Some (three common } \\
\text { scenarios) }\end{array}$} & $\begin{array}{l}\text { A. Slams on the brake pedal to activate ABS } \\
\text { then releases the brake pedal's pressure, so } \\
\text { ABS is no longer activated through the } \\
\text { remainder of the stop }\end{array}$ & $\begin{array}{l}\text { A. The nose of the vehicle dives down and the } \\
\text { wheels show the ratcheting effect, as pedal } \\
\text { pressure is released the nose of the vehicle slowly } \\
\text { rises and the wheels no longer are ratcheting }\end{array}$ \\
\hline & & $\begin{array}{l}\text { B. Eases onto pressing the brake pedal, but not } \\
\text { initially pressing hard enough to activate ABS, } \\
\text { steadily applies enough brake pedal pressure } \\
\text { to eventually activate ABS and sustain ABS } \\
\text { through the rest of the stop }\end{array}$ & $\begin{array}{l}\text { B. The nose of the vehicle slowly moves down up } \\
\text { to the point where ABS and the ratcheting effect of } \\
\text { the wheels begin, until the vehicle comes to a stop }\end{array}$ \\
\hline & & $\begin{array}{l}\text { C. Combination of both scenarios A. \& B. } \\
\text { where eases onto the brake pedal and releases } \\
\text { the pedal at the end of the stop }\end{array}$ & $\begin{array}{l}\text { Combination of both A. \& B. with the gradual } \\
\text { downward motion of the nose of the vehicle until } \\
\text { the ratcheting effect begins and the nose of the } \\
\text { vehicle begins to rise near the end of the stop } \\
\text { because ABS is no longer activated therefore the } \\
\text { ratcheting effect disappears before the driver } \\
\text { comes to a complete stop }\end{array}$ \\
\hline
\end{tabular}


Table 2. Cont.

\begin{tabular}{|c|c|c|c|}
\hline Rating & Level of Activation & Driver Action & Instructor Sees/What the Vehicle Does \\
\hline \multirow{2}{*}{4} & \multirow{2}{*}{$\begin{array}{l}\text { Most (two common } \\
\text { scenarios) }\end{array}$} & $\begin{array}{l}\text { A. Releases the pressure from the brake pedal } \\
\text { at the very end of the stop }\end{array}$ & $\begin{array}{l}\text { A. The nose of the vehicle slowly rises as the } \\
\text { vehicle comes to a stop, ratcheting of the wheels } \\
\text { stops }\end{array}$ \\
\hline & & $\begin{array}{l}\text { B. Eases onto the brake pedal at the very } \\
\text { beginning of the stop }\end{array}$ & $\begin{array}{l}\text { B. The nose of the vehicle moves down at the } \\
\text { beginning of the stop until ABS is activated and } \\
\text { the ratcheting of the wheels begins }\end{array}$ \\
\hline 5 & Full & $\begin{array}{l}\text { Slams on the brake pedal and holds the } \\
\text { pressure on the brake pedal until the vehicle } \\
\text { comes to a complete stop }\end{array}$ & $\begin{array}{l}\text { The nose of the vehicle dives at the very beginning } \\
\text { of the stop, the ratcheting (locking and releasing) } \\
\text { of the wheels begins and continues until the } \\
\text { vehicle comes to a complete stop, the nose of the } \\
\text { vehicle jumps upward when the vehicle comes to a } \\
\text { stop }\end{array}$ \\
\hline
\end{tabular}

\subsection{Procedure}

Participants were recruited by a researcher in the order they arrived at the facility before the class began. All subjects read the consent form and provided their written approval prior to participating in the study. The study was conducted in accordance with the Declaration of Helsinki, and the protocol was approved by the Ethics Committee at Clemson University. After providing consent, each participant was given a folder containing the pre-test survey and post-test survey, which was left at their table in the classroom throughout the day. Participants completed the pre-test survey before the class began. Once the pre-test was complete, participants returned the pre-test to their folder.

The beginning of the classroom portion of the class included an introduction as well as group, vehicle, and driver assignments. Individuals were assigned to a group as well as a specific car. Each car had up to two individuals, one person was assigned to drive first and the other to be a passenger first, before switching roles. Typically, there was a maximum of 16 drivers per class, so each group had up to four vehicles with eight individuals. During the driving portion of the class, participants were tracked by their group, car and driver number assigned during the classroom portion.

After the completion of the classroom and warm up driving exercise, one group performed the ABS exercise while the other group drove through a different exercise on another part of the course. The instructor communicated with the individuals in each group over two-way radios. The researchers and instructor each had two radios, one for communication with the drivers and one for communication between the instructor and researcher. While the instructor took the class through the exercise and demonstration of ABS at different speeds, the researchers positioned themselves in a vehicle off the closed-road course, but with an excellent view of the exercise.

After the instructions and demonstrations were complete, the instructor took their place near the stopping point, so they were able to see the driver. Drivers were instructed when to start the exercise and what speed to drive over the radio. The target speed for the driver to achieve was determined by the instructor and was the driver's goal to reach before braking. In some instances, the instructor was very systematic starting at $30 \mathrm{mph}$ regardless of the experience level of the class members while in other instances the instructors adjusted the speed based upon the drivers' level of experience. For the first run, the instructor suggested 30, 35, 40 or $45 \mathrm{mph}$. Speeds increased as drivers completed more runs of the ABS exercise, starting at a minimum of $30 \mathrm{mph}$ and increasing to a maximum of $60 \mathrm{mph}$. For the final run (i.e., run 7), the instructor suggested 55 or $60 \mathrm{mph}$. Once instructed, the driver sped up to the desired speed and then attempted to activate ABS by braking near the designated cones. Once the driver came to a stop, the instructor provided feedback over the radio to the driver then provided the rating to only the researcher. The driver never heard the ratings provided to the researcher. The instructor provided the driver's speed and their 1 to 5 rating using the research radio while the driver traveled back to the starting line. During pilot testing the most common instructor feedback: "Press the brake harder or Press the brake as hard as you can"; "Press the pedal and keep it 
pressed until the vehicle comes to a complete stop"; "Slam the pedal from the start instead of easing onto it"; "Look where you want the vehicle to go"; and "Begin braking at the cones, not before them" were entered onto the data sheet so they did not need to be typed each time. As the speed of the exercise increased, drivers needed to look in the direction of the path they intended to follow to steer in the correct direction. The instructors only communicated to the researchers if the driver was looking in the direction of the path they intended to go by saying "yes" or "no". All drivers completed a minimum of six runs while the majority of drivers had seven runs. After all drivers finished their runs, the driver and passenger switched roles and started the exercise over. After that group of individuals had experienced the ABS exercise as both the driver and passenger, the groups switched places on the course, and the process was repeated with the new group of drivers and passengers.

After the driving portion of the day, the participants returned to the classroom for the conclusion of the class, where the participants completed the post-test survey. Each participant filled out the post-test stored in their folder and when complete, placed the post-test back in their individual folder. The folders were collected after the class concluded.

\section{Data Organization and Analysis}

Many of the survey questions were open-ended requiring sorting, then grouping similar responses together to form categories. For example, the response category of pulsating or vibration of the brake pedal/vehicle included responses like pulsating brake pedal, vibration in foot, and shuddering in the brake pedal. After the categorization for each question was complete, the number of responses were tallied.

For the closed-road course data, the drivers' performance was examined using the instructor's ratings for the ABS runs. Much of the analyses focused on the initial ABS run since a driver on a road would only have one chance to use ABS in an emergency situation. Exploratory $t$-tests were conducted using survey responses to group drivers to explore if ABS performance varied based upon previous knowledge or experience with ABS. To identify potential differences between the ABS runs, an analysis of variance was performed. This analysis determined if the participants' performance changed with more practice and approximately how much practice was necessary.

\section{Results}

\subsection{Overview of the Initial Run of the ABS Exercise}

During the ABS exercise, the participants had multiple attempts to activate ABS by slamming on the brake pedal at various speeds. The first run of the ABS exercise (30-45 mph) was the participants' initial attempt to activate ABS on the closed-road course. The instructor ratings for the initial ABS run ranged between a 1 (no ABS activation) to 5 (full ABS activation) with an average of 3.86. First, the survey responses associated with knowledge of ABS and prior experience using ABS were investigated using independent samples $t$-tests. An independent samples t-test was conducted to explore if participants who correctly answered a question, or responded with a yes, differ from participants who incorrectly answered, or responded with a no, for the initial run of the ABS exercise, see Table 3. There were no meaningful differences on instructor ratings between the groups who did and did not previously use ABS, know what ABS stands for or understand the purpose of ABS. Instructor ratings were significantly higher when participants knew what ABS feels like when activated prior to the class with an average rating of 4.14 in comparison to a rating of 3.33 for those with no prior knowledge, $t(45.19)=2.02$, $p=0.05$, Cohen's $d=0.50$. Having additional driver training beyond driver's education $(M=4.43)$ resulted in significantly higher instructor ratings than no additional training $(M=3.63 ; t(55.64)=2.39, p<0.05, d=0.55)$. The 9 participants who had behind-thewheel experience as part of their additional training $(M=5.00)$, had significantly higher ratings than the 12 individuals who did not receive behind-the-wheel training as part of their experience $(M=4.00 ; t(11)=2.57, p<0.05)$. The largest difference between the groups was observed between participants who reported previously practicing ABS 
$(M=4.85)$ having significantly higher ratings than those who did not report prior practice $(M=3.43 ; t(63.44)=5.12, p<0.05, d=1.10)$.

Table 3. Average instructor ratings for run one for all participants based on their knowledge of ABS and previous experience using ABS.

\begin{tabular}{|c|c|c|c|c|c|c|c|c|c|c|c|c|}
\hline & \multicolumn{6}{|c|}{ Survey Response } & \multirow[b]{3}{*}{ 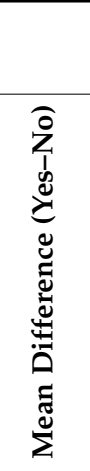 } & \multirow[b]{3}{*}{+} & \multirow[b]{3}{*}{ s } & \multirow[b]{3}{*}{2} & \multirow[b]{3}{*}{$\begin{array}{l}0 \\
0 \\
\tilde{0} \\
\tilde{d} \\
\tilde{0} \\
0\end{array}$} & \multirow[b]{3}{*}{$\begin{array}{l}\text { dे } \\
\text { zo }\end{array}$} \\
\hline & & Yes & & & No & & & & & & & \\
\hline & 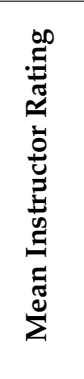 & के & $z$ & 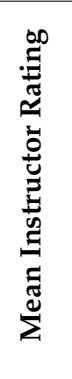 & के & z & & & & & & \\
\hline Did the participant previously use ABS? & 3.98 & 1.59 & 62 & 3.38 & 1.67 & 16 & 0.60 & 1.35 & 76 & 0.18 & 0.37 & 0.26 \\
\hline Did the participant know what ABS stands for? & 3.89 & 1.60 & 57 & 3.76 & 1.70 & 21 & 0.13 & 0.32 & 76 & 0.75 & 0.08 & 0.06 \\
\hline Did the participant know the purpose of ABS? & 4.09 & 1.47 & 53 & 3.36 & 1.82 & 25 & 0.73 & 1.76 & 39.30 & 0.09 & 0.44 & 0.43 \\
\hline $\begin{array}{l}\text { Did the participant know what ABS feels like when } \\
\text { it is activated?* }\end{array}$ & 4.14 & 1.47 & 51 & 3.33 & 1.78 & 27 & $0.81^{*}$ & 2.02 & 45.19 & 0.05 & 0.50 & 0.55 \\
\hline $\begin{array}{l}\text { Did the participant have any additional driver's } \\
\text { training? * }\end{array}$ & 4.43 & 1.12 & 21 & 3.63 & 1.73 & 56 & $0.80^{*}$ & 2.39 & 55.64 & 0.02 & 0.55 & 0.56 \\
\hline $\begin{array}{l}\text { - If yes, did that that training include ABS } \\
\text { experience? * }\end{array}$ & 5.00 & 0.00 & 9 & 4.00 & 1.35 & 12 & $1.00^{*}$ & 2.57 & 11.00 & 0.03 & Er & Er \\
\hline Did the participant ever practice using ABS? * & 4.85 & 0.61 & 26 & 3.43 & 1.72 & 47 & $1.42^{*}$ & 5.12 & 63.44 & 0.00 & 1.10 & 1.00 \\
\hline
\end{tabular}

* Significant difference between the two groups $(p<0.05)$.

A total of 48 participants received a rating of 5 on their first run, demonstrating a stop with full ABS activation (see Figure 3). Fourteen participants were given ratings of 1 , indicating there was no ABS activation during their initial run. Six participants received a rating of 2 indicating only brief ABS activation, five participants received a rating of 3 indicating some ABS activation, and five participants received a rating of 4 indicating ABS activation throughout most of the stop.

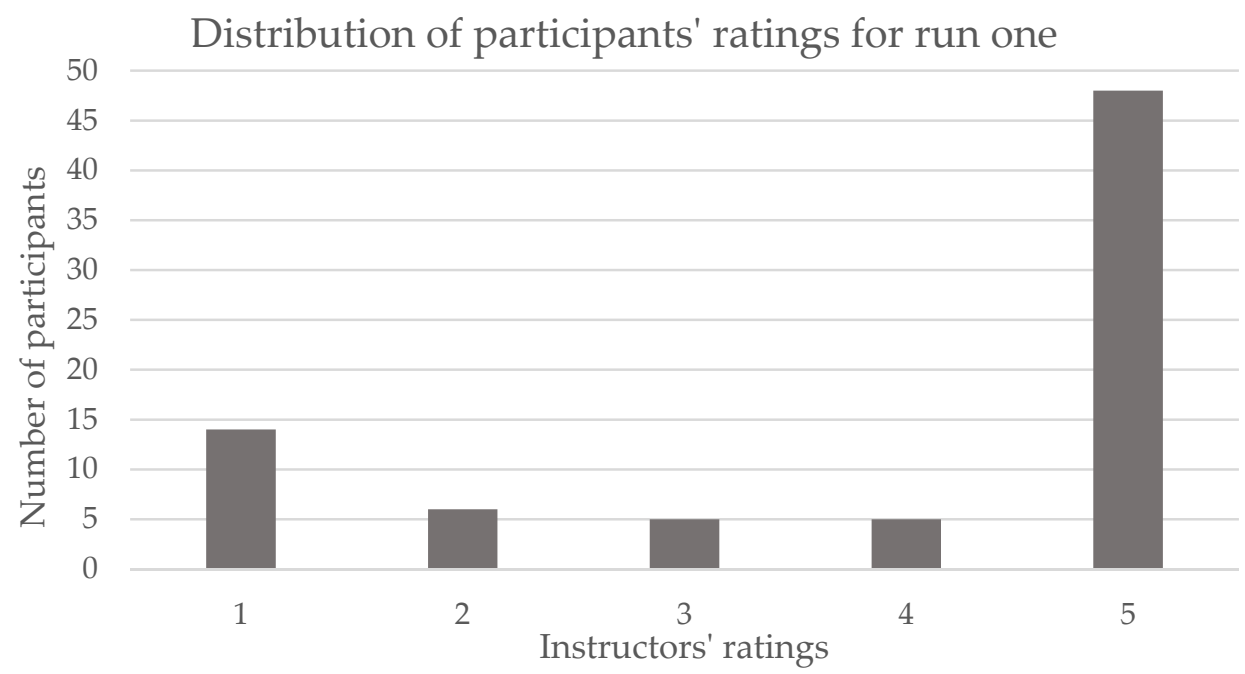

Figure 3. Number of participants that received each rating during the initial run where 1 is no ABS activation, 2 is brief ABS activation, 3 is some ABS activation, 4 is ABS activation throughout most of the stop, and 5 is full ABS activation throughout the entire stop. 
As a result of the large number of individuals who received an instructor rating of 5 on the first run, for data analysis, participants were split into two groups to explore the survey responses, a "pass" group that included drivers who received an instructor rating of 5 or a "fail" group that included drivers who received a 1 through 4 instructor rating. The pass group included 48 participants while the fail group included 30 participants. Table 4 shows each item and the percentage of participants that fell within the pass or fail group. For example, gender is split into male and female, where $67.2 \%$ of the 61 males received an instructor rating of 5 , or a pass, during the first run while $31.1 \%$ of the males received an instructor rating of 1 to 4 for the first run, thus falling into the fail group.

Table 4. Characteristics of participants that passed (instructor rating of 5) or failed (instructor rating of 1 through 4) during the first run of the ABS exercise.

\begin{tabular}{|c|c|c|c|c|}
\hline & \multirow{2}{*}{$\begin{array}{l}\text { Number of Participants } \\
(N=79)\end{array}$} & Pass & Fail & $\begin{array}{l}\text { Difference } \\
\text { (Pass-Fail) }\end{array}$ \\
\hline & & 48 & 30 & 18 \\
\hline \multirow{2}{*}{ Gender } & Male $(N=61)$ & $67.2 \%$ & $31.1 \%$ & $36.1 \%$ \\
\hline & Female $(N=18)$ & $38.9 \%$ & $61.1 \%$ & $-22.2 \%$ \\
\hline \multirow{2}{*}{$\begin{array}{l}\text { State what ABS stands for. Accepted response: anti-lock } \\
\text { braking system }\end{array}$} & Correct $(N=56)$ & $64.3 \%$ & $37.5 \%$ & $26.8 \%$ \\
\hline & Incorrect $(N=23)$ & $52.2 \%$ & $39.1 \%$ & $13.0 \%$ \\
\hline \multirow{2}{*}{$\begin{array}{l}\text { Describe the purpose of ABS. Accepted responses: keeping } \\
\text { the wheels from locking up, automatically pumping the } \\
\text { pedal, retaining the ability to steer, etc. }\end{array}$} & Correct $(N=53)$ & $66.7 \%$ & $31.5 \%$ & $35.2 \%$ \\
\hline & Incorrect $(N=23)$ & $52.2 \%$ & $47.8 \%$ & $-4.4 \%$ \\
\hline \multirow{2}{*}{$\begin{array}{l}\text { Describe what you feel when ABS is activated. Accepted } \\
\text { responses: vibration of the vehicle or brake pedal, etc. }\end{array}$} & Correct $(N=51)$ & $70.6 \%$ & $29.4 \%$ & $41.2 \%$ \\
\hline & Incorrect $(N=28)$ & $42.9 \%$ & $53.6 \%$ & $-10.7 \%$ \\
\hline \multirow{2}{*}{ Previously used ABS } & Yes $(N=62)$ & $67.7 \%$ & $32.3 \%$ & $35.5 \%$ \\
\hline & No $(N=17)$ & $35.3 \%$ & $58.8 \%$ & $-23.5 \%$ \\
\hline \multirow{3}{*}{ - If yes, what did you experience? } & $\begin{array}{l}\text { Pedal/vehicle vibration } \\
(N=34)\end{array}$ & $76.5 \%$ & $23.5 \%$ & $52.9 \%$ \\
\hline & $\begin{array}{l}\text { Braking in slick/slippery } \\
\text { conditions }(N=6)\end{array}$ & $66.6 \%$ & $33.3 \%$ & $33.3 \%$ \\
\hline & Vehicle stopped $(N=6)$ & $66.6 \%$ & $33.3 \%$ & $33.3 \%$ \\
\hline \multirow{3}{*}{$\begin{array}{l}\text { - If yes, the first time this happened to you, what did } \\
\text { you think was going on? }\end{array}$} & ABS was activating $(N=30)$ & $66.6 \%$ & $33.3 \%$ & $33.3 \%$ \\
\hline & $\begin{array}{l}\text { Problem with the vehicle } \\
(N=8)\end{array}$ & $62.5 \%$ & $37.5 \%$ & $25.0 \%$ \\
\hline & Brakes malfunctioning $(N=7)$ & $71.4 \%$ & $28.6 \%$ & $42.8 \%$ \\
\hline \multirow{2}{*}{$\begin{array}{l}\text { - If yes, at that moment, did you immediately know } \\
\text { what was happening? }\end{array}$} & Yes $(N=40)$ & $70.0 \%$ & $30.0 \%$ & $40.0 \%$ \\
\hline & No $(N=16)$ & $68.8 \%$ & $31.3 \%$ & $37.5 \%$ \\
\hline \multirow{3}{*}{ - If yes, describe the environment } & $\begin{array}{l}\text { Snow covered or icy road } \\
(N=16)\end{array}$ & $62.5 \%$ & $37.5 \%$ & $25.0 \%$ \\
\hline & Wet road/raining $(N=15)$ & $60.0 \%$ & $40.0 \%$ & $20.0 \%$ \\
\hline & $\begin{array}{l}\text { Emergency stop was necessary } \\
(N=11)\end{array}$ & $54.6 \%$ & $45.4 \%$ & $9.0 \%$ \\
\hline \multirow{2}{*}{ Previously practiced using ABS * } & Yes $(N=26)$ & $92.3 \%$ & $7.7 \%$ & $84.6 \%$ \\
\hline & No $(N=47)$ & $46.8 \%$ & $53.2 \%$ & $-6.4 \%$ \\
\hline \multirow{2}{*}{$\begin{array}{l}\text { Any additional driver's training outside of driver's } \\
\text { education }\end{array}$} & Yes $(N=22)$ & $72.7 \%$ & $22.7 \%$ & $50.0 \%$ \\
\hline & No $(N=56)$ & $55.4 \%$ & $44.6 \%$ & $10.7 \%$ \\
\hline \multirow{2}{*}{ - $\quad$ If yes, ABS experience part of the additional training $* *$} & Yes $(\mathrm{N}=11)$ & $81.8 \%$ & $0.0 \%$ & $81.8 \%$ \\
\hline & No $(N=11)$ & $63.6 \%$ & $36.4 \%$ & $27.2 \%$ \\
\hline
\end{tabular}


Table 4. Cont.

\begin{tabular}{|c|c|c|c|c|}
\hline & \multirow{2}{*}{$\begin{array}{l}\text { Number of Participants } \\
(N=79)\end{array}$} & Pass & Fail & $\begin{array}{l}\text { Difference } \\
\text { (Pass-Fail) }\end{array}$ \\
\hline & & 48 & 30 & 18 \\
\hline \multirow{2}{*}{$\begin{array}{l}\text { Experiencing the ABS exercise as a driver versus } \\
\text { passenger first }\end{array}$} & Driver first $(N=40)$ & $55.0 \%$ & $42.5 \%$ & $12.5 \%$ \\
\hline & Passenger first $(N=39)$ & $66.7 \%$ & $33.3 \%$ & $33.3 \%$ \\
\hline \multirow{2}{*}{$\begin{array}{l}\text { Group order (first or second group to experience ABS } \\
\text { exercise) }\end{array}$} & First $(N=42)$ & $71.4 \%$ & $26.2 \%$ & $45.2 \%$ \\
\hline & Second $(N=37)$ & $48.6 \%$ & $51.4 \%$ & $-2.7 \%$ \\
\hline \multirow{3}{*}{ What was the hardest part about the ABS exercise? } & $\begin{array}{l}\text { Maintaining pedal pressure } \\
\text { until the vehicle stopped } \\
(N=18)\end{array}$ & $50.0 \%$ & $50.0 \%$ & $0.0 \%$ \\
\hline & $\begin{array}{l}\text { Pressing the pedal hard } \\
\text { enough }(N=15)\end{array}$ & $60.0 \%$ & $40.0 \%$ & $20.0 \%$ \\
\hline & $\begin{array}{l}\text { Looking where you want the } \\
\text { vehicle to go }(N=10)\end{array}$ & $60.0 \%$ & $40.0 \%$ & $20.0 \%$ \\
\hline \multirow{2}{*}{$\begin{array}{l}\text { Has today's class changed your understanding of what ABS } \\
\text { is, how it works, or what the driver feels? }\end{array}$} & Yes $(N=46)$ & $54.3 \%$ & $43.5 \%$ & $10.9 \%$ \\
\hline & No $(N=31)$ & $67.7 \%$ & $32.3 \%$ & $35.5 \%$ \\
\hline \multirow{3}{*}{$\begin{array}{l}\text { - If yes, what do you know now that you did not know } \\
\text { before? }\end{array}$} & How ABS works $(N=8)$ & $50.0 \%$ & $50.0 \%$ & $0.0 \%$ \\
\hline & $\begin{array}{l}\text { How ABS feels when activated } \\
(N=6)\end{array}$ & $66.7 \%$ & $33.3 \%$ & $33.3 \%$ \\
\hline & Ability to steer $(N=6)$ & $33.3 \%$ & $66.7 \%$ & $-33.3 \%$ \\
\hline
\end{tabular}

${ }^{*}$ Note: Six participants reported not knowing if they had previously practiced using ABS. ${ }^{* *}$ Note: Data collection error where instructor rating was not recorded for two participants.

In comparison to drivers who failed their first ABS run (received an instructor rating of 1 through 4), the drivers who passed (received a rating of 5) had higher percentages for knowing what ABS stands for (64.3\%), accurately describing the purpose of ABS (66.7\%), and accurately describing what the driver feels when ABS is activated (70.6\%). Those who passed the first run had more previous experience with ABS (67.7\%) where most described experiencing pedal or vehicle vibration. Some of the greatest differentiators of those who passed versus those who did not pass were previous experience practicing ABS (92.3\%), additional driver's training beyond driver's education (72.7\%), and additional training that included ABS experience (81.8\%). Participants described where and/or who they practiced with; the pass group answers consisted of post-license driving courses like the car control class $(27.3 \%)$, in a parking lot $(22.7 \%)$ or with family/friends $(22.7 \%)$. Only two participants who reported practicing using ABS were in the fail group, where one participant described their practice as a car club class and the other participant practiced on their own and in driver's education. The research team was curious if observing the ABS exercise prior to driving or completing the ABS exercise or a different exercise would dramatically increase the pass rate of the latter opportunity, but neither case appeared to be dramatically more beneficial.

\subsection{Overview of Runs One through Seven}

On run one, the instructors gave target speeds of $30,35,40$ and $45 \mathrm{mph}$, with an average of $32.3 \mathrm{mph}(S D=5.2 \mathrm{mph})$. The majority of participants completed seven runs during the ABS exercise (see Table 5. To investigate if run number influenced ABS performance, a two-way analysis of variance was conducted. The results show that the run number had a significant impact on performance where ABS ratings increased with run number $\left(F(6,529)=9.17, p<0.05, \eta^{2}=0.09\right)$. Games-Howell post-hoc comparisons were used because equal variance was not assumed. The average rating for run one $(M=3.86)$ was significantly lower than runs three $(M=4.66)$, five $(M=4.68)$, six $(M=4.85)$ and seven 
$(M=4.71)$. The average ratings on run two $(M=4.46)$ and run four $(M=4.48)$ were significantly lower than run $6(M=4.85)$.

Table 5. The target speed provided by the instructors (which varied between drivers, therefore the range, average speed, standard deviation (SD) are included as well as the instructors' average ABS rating and standard deviation. Since the sample size varied slightly for each run, the sample size is also included.

\begin{tabular}{|c|c|c|c|c|c|c|c|}
\hline \multirow{2}{*}{ Run } & \multicolumn{2}{|c|}{$\begin{array}{l}\text { Instructor Suggested Speed } \\
\text { (mph) }\end{array}$} & \multirow{2}{*}{$\begin{array}{c}\text { Average } \\
\text { Speed (mph) }\end{array}$} & \multirow{2}{*}{ Speed $S D$} & \multirow{2}{*}{$\begin{array}{c}\text { Average ABS } \\
\text { Instructor } \\
\text { Rating }\end{array}$} & \multirow{2}{*}{$\begin{array}{c}\text { ABS } \\
\text { Instructor } \\
\text { Rating } S D\end{array}$} & \multirow{2}{*}{ Sample Size } \\
\hline & Min & Max & & & & & \\
\hline 1 & 30 & 45 & 32.3 & 5.24 & 3.86 & 1.62 & 78 \\
\hline 2 & 40 & 50 & 41.0 & 2.45 & 4.46 & 1.00 & 78 \\
\hline 3 & 40 & 50 & 45.7 & 2.08 & 4.66 & 0.71 & 79 \\
\hline 4 & 45 & 55 & 50.1 & 1.26 & 4.48 & 0.88 & 77 \\
\hline 5 & 45 & 60 & 54.6 & 2.29 & 4.67 & 0.82 & 78 \\
\hline 6 & 50 & 60 & 58.7 & 2.46 & 4.85 & 0.43 & 78 \\
\hline 7 & 55 & 60 & 59.8 & 0.87 & 4.71 & 0.69 & 68 \\
\hline
\end{tabular}

Next, the distribution of the drivers' performance was explored by graphing the percentage of drivers who received each of the 5 possible ratings. First, the distribution of all 79 drivers is shown in Figure $4 \mathrm{a}$ with the percentage of 1 through 5 ratings that compose each of the seven runs. Since 25 drivers received an instructor rating of 5, demonstrating a stop with full ABS activation on all 7 runs, those 25 individuals' data were removed from Figure $4 \mathrm{~b}$ which shows the same distribution of 1 through 5 ratings for all seven runs for the remaining 54 drivers. On Figure $4 b, 56.6 \%$ of the participants received a $1-4$ instructor rating (fail) on run one, $43.3 \%$ received a $1-4$ rating on run two, 33.3\% received a $1-4$ rating on run three, $48.1 \%$ received a $1-4$ rating on run four, $28.3 \%$ received a $1-4$ rating on run five, $18.9 \%$ received a $1-4$ rating on run six, and $25.0 \%$ received a 1-4 rating on run seven. In comparison to the other runs, run one had the largest percentage of instructor ratings of 1 and 2 with $26.4 \%$ and $11.3 \%$, respectively (see Figure $4 \mathrm{~b}$ ). Run four had the highest percentage of both 3 and 4 rating compared to the other runs with $15.4 \%$ and $26.9 \%$, respectively.

There were $24.1 \%$ of the participants who received an instructor rating of 5 on all of the runs except one run, 12 participants received all but two ratings of 5 on all runs, four participants received all but three ratings of 5 on all runs, 15 participants received all but four ratings of 5 on all runs, and three participants received all but five ratings of 5 on all runs. One participant never received a rating of 5 .

While the majority of participants (48) were able to fully activate ABS during their first run, other participants needed multiple runs in order to improve their skill and receive an instructor rating of 5, see Figure 5. A total of 14 participants needed two runs, 8 participants needed three runs, five participants needed four runs, two needed five runs, one needed six runs and the final driver was unable to gain a rating of 5 within seven runs, this participant's maximum instructor rating was 4 . 


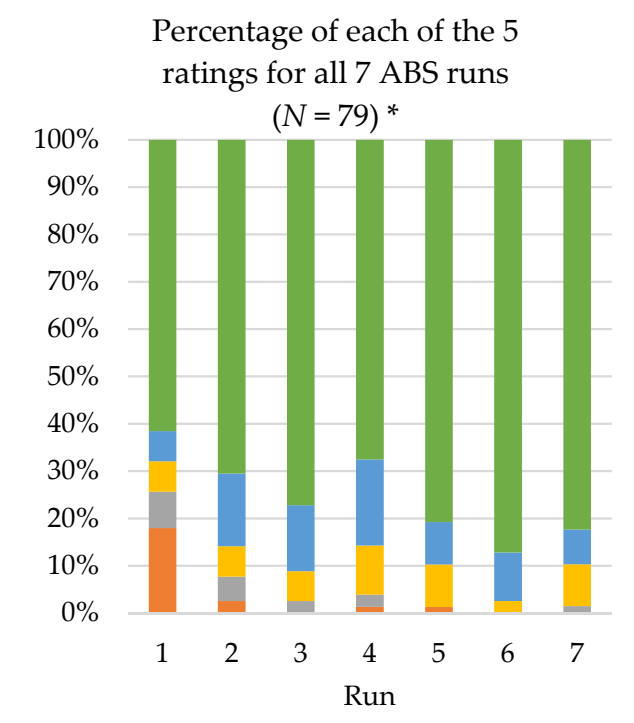

(a)
Percentage of each of the 5 ratings for all 7 runs with participants receiving $5 \mathrm{~s}$ for all runs excluded $(N=54) * *$

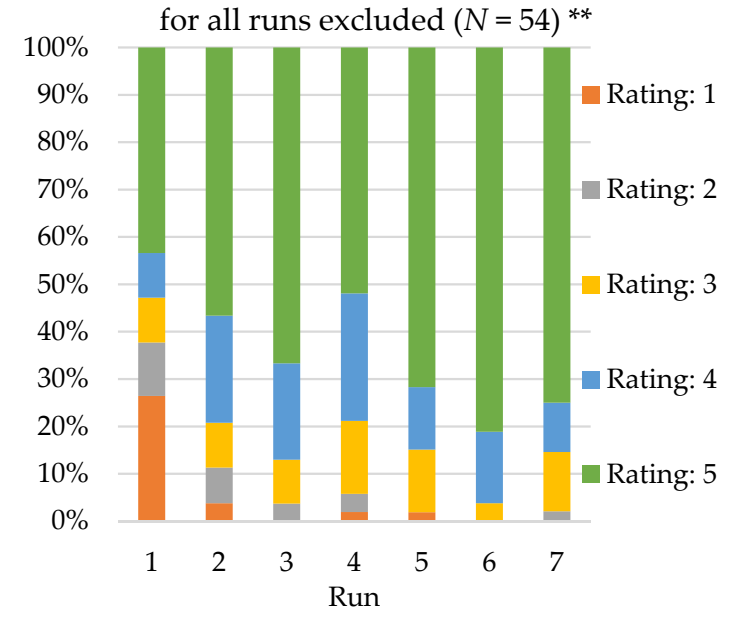

(b)

Figure 4. (a) The percentage of $1-5$ instructor ratings for the 7 runs for all 79 participants (b) The percentage of 1-5 instructor ratings for the runs without the 25 participants who received a perfect instructor rating of 5 for all runs in (a), * Runs 1-6 fluctuated slightly between 77-79 participants due to data collection errors, run 7 had 68 participants due to time limitations. ** Runs 1-6 fluctuated between 52-54 participants due to data collection errors, run 7 had 48 participants due to time limitations.

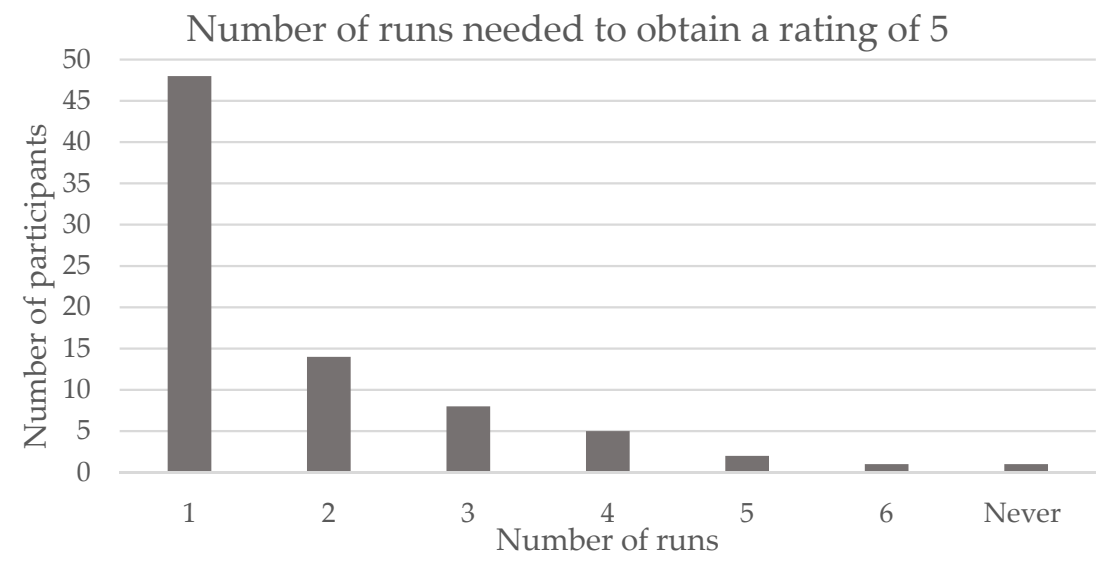

Figure 5. Number of runs needed to obtain an instructor rating of 5 .

\subsection{Instructor Feedback}

During the exercise, drivers received feedback on their performance after each run. While all drivers received feedback after each run, only constructive comments were recorded. The feedback fell into five topical areas, the instructors provided each of the five comments from 56 to 27 times (the number of total times each type of feedback was given is in parentheses, see Table 6): "Press the pedal and keep it pressed until the vehicle comes to a complete stop" (56); "Look where you want the vehicle to go" (53); "Press the brake harder or Press the brake as hard as you can" (49); "Slam the pedal from the start (of the stop) instead of easing onto it" (31); and "Begin braking at the cones, not before them" (27). While the number of comments decreased as the number of runs increased, the type of feedback given to the participants also changed as the number of runs increased. Run one had the highest number of "Press the brake harder or Press the brake as hard as you can" (21) and "Begin braking at the cones, not before them" (11). As the number of runs and speed increased (runs three through six), the feedback changed to include "Press the pedal and keep it pressed until the vehicle comes to a complete stop" (56) and "Look where you want the vehicle to go" (53). 
Table 6. Feedback given to drivers during each run

\begin{tabular}{|c|c|c|c|c|c|c|c|c|c|c|}
\hline & & \multirow{2}{*}{\multicolumn{2}{|c|}{$\begin{array}{l}\text { Instructor Suggested } \\
\text { Target Speed (mph) }\end{array}$}} & \multirow{3}{*}{$\begin{array}{l}\text { Avg. Speed } \\
\text { (mph) }\end{array}$} & \multirow{3}{*}{$\begin{array}{l}\text { Press the Pedal and Keep It } \\
\text { Pressed until the Vehicle } \\
\text { Comes to a Complete Stop }\end{array}$} & \multicolumn{3}{|c|}{ Feedback } & \multirow{3}{*}{$\begin{array}{l}\text { Begin Braking at } \\
\text { the Cones, Not } \\
\text { before }\end{array}$} & \multirow{3}{*}{$\begin{array}{l}\text { Comment } \\
\text { Count for } \\
\text { Each Run }\end{array}$} \\
\hline & & & & & & $\begin{array}{l}\text { Look Where You } \\
\text { Want the Vehicle to }\end{array}$ & $\begin{array}{l}\text { Press the Brake } \\
\text { Harder or as Hard }\end{array}$ & $\begin{array}{l}\text { Slam the Pedal from } \\
\text { the Start Instead of }\end{array}$ & & \\
\hline & & Min & Max & & & & as You Can & Easing onto It & & \\
\hline \multirow{7}{*}{ 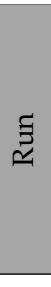 } & 1 & 30 & 45 & 32.3 & 4 & 1 & 21 & 9 & 11 & 46 \\
\hline & 2 & 40 & 50 & 41.0 & 6 & 3 & 10 & 6 & 5 & 30 \\
\hline & 3 & 40 & 50 & 45.7 & 10 & 10 & 6 & 7 & 1 & 34 \\
\hline & 4 & 45 & 55 & 50.1 & 9 & 8 & 5 & 6 & 2 & 30 \\
\hline & 5 & 45 & 60 & 54.6 & 12 & 13 & 3 & 0 & 3 & 31 \\
\hline & 6 & 50 & 60 & 58.7 & 8 & 11 & 1 & 1 & 3 & 24 \\
\hline & 7 & 55 & 60 & 59.8 & 7 & 7 & 3 & 2 & 2 & 21 \\
\hline & \multicolumn{4}{|c|}{ Count for each type of feedback } & 56 & 53 & 49 & 31 & 27 & \\
\hline
\end{tabular}




\section{Discussion}

The goal of this study was to increase the body of literature regarding drivers' ability to activate ABS and determine if prior knowledge and/or experience impact drivers' performance activating ABS. Seventy-nine participants ranging in age from 18 to 78 years with an average age of 45 , were recruited from car control classes that focused on defensive driving skills, with classroom and behind-the-wheel instruction on a closed-road course from professional driving instructors. Gaining knowledge and experience activating the anti-lock braking system (ABS) is one focus of the class. Based on a previous survey study [21], having the opportunity to practice activating ABS on the closed-road course was reported as one of the most important and most used skills on the road after the class. To further explore drivers' understanding and ability to activate ABS, instructors rated drivers' ability to activate ABS on the closed-road course in addition to the participants completing of pre- and post-test surveys. The pre-test survey aimed to gain participants' knowledge of ABS as well as their previous experience activating ABS. During the behindthe-wheel instruction, ABS activation was rated by the instructors using a 1-5 behaviorally anchored rating scale focusing on the driver's ability to activate ABS, where a rating of 1 indicated no ABS activation and 5 indicated that ABS was fully activated throughout the entire stop. The post-test survey targeted participants change in understanding of ABS after the class. Since individuals enrolled in the car control classes are often enthusiasts of the BMW brand and/or driving, unlike the typical US driver, some of the participants enrolled in the car control class may have more driving experience and knowledge than the typical driver. The participant population had a broad age span and varying levels of prior experience with ABS, these characteristics are not observed in other studies $[19,20]$.

In a real-world driving scenario, a driver would only have one chance to activate ABS, therefore the results of the initial run of the ABS task was analyzed separately from all 7 runs. For the initial run, a total of 48 of the 79 participants $(60.8 \%)$ received an instructor rating of 5, indicating full ABS activation during the entire stop. While it is unknown what percentage of the entire driving population can achieve full ABS activation during an emergency stop, it is likely this level of success $(60.8 \%)$ is greater than the general driving population due to the participants who self-select to attend courses such as the car control classes. To better understand the attributes of the participants that were able to fully activate ABS on the first run, participants were divided into two groups, pass (instructor rating of 5) or fail (instructor rating of 1 to 4 ). Responses from the pre- and post-test survey responses were explored for both the pass and fail groups. The participants in the pass group had more experience with ABS, including $92.3 \%$ of participants reported previously practicing using ABS, $72.7 \%$ of participants had additional training outside of driver's education, and $67.7 \%$ of participants previously experienced ABS. For the participants in the pass group, $70.6 \%$ accurately described what the driver feels when ABS is activated, $66.7 \%$ correctly stated the purpose of ABS, and $64.3 \%$ correctly identified what ABS stands for. The combination of the instructor ratings plus the survey data, demonstrated that both previous knowledge of $A B S$ and experience using $A B S$ were associated with full ABS activation (instructor rating of 5) during the first run.

Next, regardless of performance on run one, participants who reported previous experience using ABS on their pre-test survey were asked follow-up questions. There were 49 participants that reported previously experiencing ABS prior to the class. Forty-two of the 49 participants who reported previous ABS experience, were in the pass group for run one. First, participants were asked what they experienced when ABS was activated. For those that reported experiencing pedal/vehicle vibration, $76.5 \%$ were members of the 42 pass group participants in the present study. When asked if they knew what was happening the first time they activated ABS, $68.7 \%$ of those who said no were members of the 42 pass group participants in the present study. Though many of the pass group participants with prior ABS experience reported knowing that ABS was activating the first time they experienced ABS, some of the participants in the 42 pass group thought there were issues with the vehicle or the brakes the first time they experienced ABS. The 
last follow-up question asked participants to describe the environment where they first experienced ABS. The most common responses were snow covered roads, icy roads, wet roads, or when an emergency stop was necessary. In many of these cases the likelihood of losing traction is increased due to the decrease in tire traction from the water, snow, or ice on the road. A study conducted by Williams and Wells [23], found that drivers who lived in colder climates with more snow and ice (Wisconsin, USA) reported more experience with ABS than those who lived in areas with less snow and ice (North Carolina, USA). Though ABS is more inclined to activate during emergency stops on slippery roads, it is unknown if some drivers think ABS only activates in slippery conditions. If drivers do not understand that $\mathrm{ABS}$ functions under all road conditions, they may not know to activate ABS in an emergency braking situation or be surprised when ABS is activated, which could cause panic in some drivers.

When looking at the average instructor rating for each of the seven runs for all participants, the three runs with the lowest average instructor ratings were run one $(M=3.86)$, two $(M=4.46)$ and four $(M=4.48)$. The instructor's suggested speed ranged from 30 to $45 \mathrm{mph}(M=32.3)$ for run one and increased to 40 to $50 \mathrm{mph}(M=41.0)$ for run two. Though there was a progressive increase in speed from the first to second run, the overall average instructor rating improved by 0.6 . While ABS performance steadily increased for the first three runs, performance on run four decreased $(M=4.48)$. During the fourth run, the instructors increased the speed between 45 to $55 \mathrm{mph}(M=50.1)$. Steering input was needed in most runs when the speed was above $50 \mathrm{mph}$, due to the curve at the end of the course where the ABS exercise took place. The fourth run was typically where participants began adding steering input while trying to activate ABS because of the increased stopping distance associated with higher speeds. The combination of steering input and ABS activation was difficult for some participants, which could be a factor in why the average instructor rating for the fourth run was lower than the third, and fifth through seventh runs. Performance activating ABS may be affected, or even decreased when steering input is required by the driver.

There were 25 participants who slammed on the brake pedal and held the pressure on the brake pedal until the vehicle came to a complete stop during each run and thus received instructor ratings of 5 for all runs. This was uncommon with the remaining 54 participants. Though the first run yielded 48 participants receiving an instructor rating of 5, 23 participants received at least one instructor rating of 1 through 4 in the remaining runs. The majority (54) of participants were not able to attain or sustain full activation of ABS during every run. As the number of runs increased, the average instructor rating increased (excluding run four), until run six with the highest average instructor rating $(M=4.85)$. Some participants needed additional runs to fully activate ABS throughout the entire stop to receive an instructor rating of 5 .

After each run, participants were given feedback by the instructors based on their performance activating ABS. For all participants on all runs collectively, the three most common types of feedback by the instructor were: Press the pedal and keep it pressed until the vehicle comes to a complete stop; Look where you want the vehicle to go; and Press the brake harder or Press the brake as hard as you can. This instructor feedback is consistent with what participants reported as the hardest parts of the ABS exercise, which included maintaining pedal pressure until the vehicle comes to a stop $(N=18)$, pressing the pedal hard enough $(N=15)$ and looking where you want the vehicle to go $(N=10)$. Many of the participants had difficulty pressing the brake pedal hard enough, but also, once the pedal was pressed to maximum, sustaining the pressure to keep ABS activated throughout the entire stop.

When comparing the study discussed in this paper with other ABS training studies, there are some differences. The study examining the effectiveness of the low-cost training method using an informational pamphlet by Mollenhauer, Dingus, Carney, Hanley and Jahns [19], showed that participants that reviewed the pamphlet stopped on average $35 \mathrm{ft}$ sooner compared to the group of drivers that did not review the pamphlet when asked to 
stop as quickly as possible. In the Mollenhauer et al. [19] study, participants were given a pamphlet to review, where the car control classes provide information in a classroom setting where participants are encouraged to ask questions. Another difference is the sample population; the age of participants in the Mollenhauer et al. [19] study ranged from 20-26 with no prior ABS experience. In the current study, the average driver age is 45.5 and the range extends to drivers up to 78 years old. Some older drivers were taught to drive in vehicles without $A B S$, thus they may have different reactions to ABS than younger drivers. The Mollenhauer et al. [19] study recruited participants that had no prior experience with ABS. Though there was a control group to see if the pamphlet made an impact on drivers who did not have prior experience with ABS, it is unknown how the pamphlet would affect drivers with prior ABS experience. The results of the current study showed that some of the participants reported that the first time they activated ABS they did not understand that ABS was activated, similar to the findings of NTHSA's Light Vehicle Program that showed some drivers did not understand when ABS was being activated [6]. Though some of the participants may have reported previously experiencing ABS, that experience did not equate to an accurate understanding or competency in performing a full ABS stop. The drivers that take car control classes at the performance center are enthusiasts, both for the BMW brand and for driving. The majority of the US population does not drive luxury or performance focused vehicles, nor are they driving enthusiasts. Though there was variation in knowledge and prior experience with ABS, 31.6\% of participants demonstrated full activation of ABS over all runs, showing proficiency in their ability to activate ABS. Unlike other ABS studies, including the varying levels of knowledge and experience helped to better understand how prior knowledge and experience can influence performance activating ABS.

The Petersen et al. [20] study compared a group of drivers that were enrolled in a twoday post-license driving program that received ABS training with a control group of drivers not enrolled in the program. Like the Mollenhauer et al. [19] study, the Petersen et al. [20] study consisted of younger drivers. The group that received the training group had an average age of 31.7 years and 14.2 average years of driving experience, and the control group had an average age of 27.9 and 9.2 average years of driving experience. It is unknown how the two-day post-license driving program would affect the performance of drivers with more driving experience. Another major difference between the Petersen et al. [20] study and the current study, is the braking technique taught. The Petersen et al. [20] study used a two-phase braking technique, where the driver depresses the pedal quickly until near maximum and then steadily applies pressure until the pedal is fully depressed. In the current study, participants are taught to press the brake pedal as hard as possible and hold the pedal in the fully depressed position until the vehicle comes to a complete stop. The results of the Petersen et al. [20] study show longer stopping distances for drivers that had the two-phase training when compared to a control group. Since the two-phase technique requires drivers to steadily press the pedal as part of the second phase, this may cause the drivers to take longer distances to stop in comparison to a driver slamming and holding the brake. Further investigation is needed to see how the differences in technique affect stopping distance and ability to activate ABS.

The BMW performance center also hosts a non-profit event, the Guard Your Life Challenge (GYL), which is a half-day program offered to 30 teen (ages 15 to 18 years) drivers per class. The program focuses on ABS braking, skid recovery and distracted driving. In order to understand the views of the teen drivers a survey was completed by 134 volunteers directly after the program as well as a phone interview by 50 volunteers three months later. The results of the survey suggest that learning about ABS was one of the most important topics the teens learned about during the program, both directly after the program and three months later. The results of the phone interview suggest that participants avoided crashes and used the skills related to ABS braking within three months after the program [24]. Parents are required to stay for the classroom portion of the GYL program. As a result, a study was conducted with the parents to see if they 
benefitted from observing the program as well as their teens driving on the course [25]. A total of 134 parents completed the survey; the results showed that the majority of parents $(85 \%)$ had previously experienced ABS, but only $16 \%$ of the parents described their participation in previous ABS training. Fifty-three percent of parents reported teaching their teen about ABS, where the majority $(87 \%)$ had a discussion with their teen and only $13 \%$ used hands-on practice. Parents identified ABS braking as one of the most important topics that their teen learned as a result of the program, which is consistent with the teens' views. Seventy percent of parents reported that they would consider additional training for themselves after observing the teen program. The GYL program utilizes a subset of the classroom information on ABS and ABS exercise as the car control classes in the current study. Though the survey studies [24,25] do not provide ABS performance information, these studies surveyed a population of teens and parents enrolled in a half day driving program with essentially double the group size. Not many of the parents surveyed from the GYL program had been trained to activate ABS, nor did many use hands-on techniques to teach their teen about ABS [25]. Knowledge and proper activation of ABS may not be known by typical teen and adult drivers.

Though there were some participants from the car control class that performed well, not all participants were able to fully activate ABS on every run. The group of drivers in the car control classes may have more prior driving experience and practice activating ABS than typical drivers, but some of the participants needed multiple runs to activate ABS. The typical driving population may or may not need additional runs than the group of participants in the car control class, particularly if they do not have prior knowledge and experience with ABS. The results of this study show the differences that knowledge and experience activating ABS have on a participants' ability to activate ABS. The more knowledge and increased experience a participant had with ABS, the higher the instructor rating typically was. One of the biggest differentiators was prior practice and training with ABS, where participants who reported practicing using ABS before the class had an average instructor rating of 4.85 and those who had ABS experience during additional training had an average instructor rating of 5 during the first run. Though understanding ABS and experiencing it made differences in the participant's performance activating ABS, intentional practice or training was a major factor in participants' gaining instructor ratings of 5 on the first run. Interestingly, the results yielded no significant difference in average instructor ratings between participants that were the driver versus the passenger first during the exercise, even though $66.7 \%$ of pass group participants were passengers first. This may indicate that observation may not be an effective learning method. Drivers may require behind-the-wheel practice or training to fully activate ABS in scenarios where it is necessary; this is consistent with previous NHTSA research that encouraged drivers to practice activating ABS under varying conditions [26], suggesting the need for behind-thewheel practice, where the driver is actively trying to use ABS.

The action of emergency braking involves the cognitive awareness and realization of the perceived need to stop followed by the action of moving one's foot to the brake pedal and slamming on the brake. In previous research, time to perceive and act has been studied by drivers in vehicles as well as through mathematical models [27]. These studies and mathematical models rely on the presentation of a stimulus that the user must perceive and then make the appropriate action [28,29], which is consistent with an emergency braking scenario. During the ABS exercise in this study, drivers actively attempted to activate ABS, and the cones, which served as the stimulus for the braking location, were visible throughout the exercise. The driver estimated where to initiate the braking action based on the distance they were from the cones. The driver's perception-response time during the ABS exercise may not be consistent with previous studies or models that depend on a "surprise" presentation of a stimulus. However, the cones are an effective, safe, reliable and economical method to gain experience engaging ABS to maximize a safe training environment for both the driver and the instructor. 


\section{Study Limitations}

Due to the unique population that enrolls in driving classes, the results may be skewed towards evaluating driving enthusiasts' performance activating ABS. Performance ratings data during the ABS exercise were collected from three different instructors. Some of the instructors were systematic, providing participants the same number of runs at each specific speed while other instructors varied the number of runs and suggested speed based on the classes' level of experience and individual's performance activating ABS.

\section{Conclusions}

The overarching goal of this study was to quantify performance activating ABS with participants' previous knowledge of and experience with ABS. Participants' performance was rated by the professional driving instructors using a behaviorally anchored rating scale, where a rating of 1 corresponded with no ABS activation and a 5 indicated full ABS activation throughout the stop. The results of the study showed that $60 \%$ of the participants were able to fully activate ABS during their first of several runs. Participants who self-reported to have prior training (5.00) or practice (4.85) using ABS had significantly higher performance activating ABS on their first run, compared to those without previous practice or training. Not all participants were able to activate ABS during their first run, but the majority were successful at least once during the seven runs. For the participants who were not able to fully activate ABS, the most common feedback provided by the driving instructors was to maintain pedal pressure through the entire stop (56), look where you want the vehicle to go (53) and to press the brake pedal harder (49). Since the drivers with prior practice or training had the best performance activating ABS, especially during the initial runs, the results suggest that practice or training may be beneficial. Further investigation should explore different practice methods and the amount of practice necessary to use ABS in a dynamic environment where the driver can't anticipate when the emergency stop will need to occur.

\section{Future Research}

Future studies should explore differences in performance between various methods of practice with $A B S$ in order to better understand what type of practice drivers need to activate ABS in an emergency situation. Further investigations should include comparing individuals that practice activating ABS on their own versus those who had completed formal training. Future research should explore objective methods to quantify braking performance to allow for greater understanding of the braking behaviors to better understand performance deficiencies associated with varying methods of practice. These measures could include parameters like perception-response time, pedal force and/or stopping distance. Future research should assess participants' perception of their ability to activate ABS prior to receiving feedback from the driving instructor to understand the participants perception of their own performance in comparison to their actual performance. Many of the participants reported experiencing ABS in a slippery environment, future efforts should investigate participants' understanding of ABS in a variety of environments to explore if participants think ABS only activates in certain environmental conditions like snow. With the rapid changes in technology in vehicles surrounding user interfaces, future research should aim to investigate how these different types of interfaces could provide guided practice for drivers for various safety features like ABS.

Author Contributions: Conceptualization, L.M., J.O.B. and D.G.; methodology, L.M., J.O.B., C.J. and D.G.; formal analysis, L.M.; investigation, L.M., J.O.B., T.M.J., C.J., D.I., A.B. and L.H.; resources, J.O.B. and D.G.; writing — original draft preparation, L.M; writing—review and editing, L.M., J.O.B., T.M.J., C.J., J.N., D.I., A.B., L.H. and D.G.; visualization, L.M.; supervision, J.O.B.; project administration, J.O.B. and D.G. All authors have read and agreed to the published version of the manuscript.

Funding: This research received no external funding. 
Institutional Review Board Statement: The study was conducted according to the guidelines of the Declaration of Helsinki, and approved by the Institutional Review Board (or Ethics Committee) of Clemson University (protocol code IRB2017-215 and date of approval 6/12/2019).

Informed Consent Statement: Informed consent was obtained from all subjects involved in the study.

Acknowledgments: We are grateful to the dedicated instructors and logistics professionals at the BMW Performance Center. This study was made possible due to their support and teamwork. We would also like to thank the Clemson's University Professional Internship and Co-op Program (UPIC) for their support of a summer intern.

Conflicts of Interest: Daniel Gubitosa, Donnie Isley, Allison Borman and Laura Hayes are employed at the BMW Performance Center.

\section{References}

1. World Health Organization. Road Traffic Injuries; World Health Organization: Geneva, Switzerland, 2020. Available online: https:/ / www.who.int/news-room/fact-sheets/detail/road-traffic-injuries (accessed on 18 November 2020).

2. Singh, S. Critical Reasons for Crashes Investigated in the National Motor Vehicle Crash Causation Survey; Report No. DOT HS 812 506; National Highway Traffic Safety Administration: Washington, DC, USA, 2018.

3. Duffy, J.E. Modern Automotive Technology; Goodheart-Willcox Pub: Tinley Park, IL, USA, 2009.

4. Kahane, C.J. Preliminary Evaluation of the Effectiveness of Antilock Brake Systems for Passenger Cars; Report No. DOT HS 808 206; National Highway Traffic Safety Administration: Washington, DC, USA, 1994.

5. Garrott, W.R.; Mazzae, E.N. An Overview of the National Highway Traffic Safety Administration's Light Vehicle Antilock Brake Systems Research Program; Report No. 1999-01-1286; SAE Technical Paper; SAE: Detroit, MI, USA, 1999.

6. $\quad$ Mazzae, E.N.; Garrott, W.R.; Snyder, A. NHTSA Light Vehicle Antilock Brake System Research Program Task 2: National Telephone Survey of Driver Experiences and Expectations Regarding Conventional Brakes Versus ABS; Report No. DOT HS 809 429; National Highway Traffic Safety Administration: Washington, DC, USA, 2001.

7. Kahane, C.J.; Dang, J.N. The Long-Term Effect of ABS in Passenger Cars and LTVs; Report No. DOT HS 811 182; National Highway Traffic Safety Administration: Washington, DC, USA, 2009.

8. NHTS Administration. Federal Motor Vehicle Safety Standards; Electronic Stability Control Systems; Controls and Displays; Federal Rule, FMVSS, 126; National Highway Traffic Safety Administration: Washington, DC, USA, 2007.

9. Kahane, C.J. Updated Estimates of Fatality Reduction by Electronic Stability Control; Evaluation Note. Report No. DOT HS 812 020; National Highway Traffic Safety Administration: Washington, DC, USA, 2014.

10. Sivinski, R. Crash Prevention Effectiveness of Light-Vehicle Electronic Stability Control: An Update of the 2007 NHTSA Evaluation; Report No. DOT HS 811 486; National Highway Traffic Safety Administration: Washington, DC, USA, 2011.

11. Webb, C.N. Estimating Lives Saved by Electronic Stability Control, 2011-2015; Traffic Safety Facts Research Note. Report No. DOT HS 812 391; National Highway Traffic Safety Administration: Washington, DC, USA, 2017.

12. Dang, J.N. Preliminary Results Analyzing the Effectiveness of Electronic Stability Control (ESC) Systems; Evaluation Note No. DOT HS 809 790; National Highway Traffic Safety Administration: Washington, DC, USA, 2004.

13. NHTS Administration. Traffic Safety Facts 2015; Report No. DOT HS 812 384; National Highway Traffic Safety Administration's National Center for Statistics and Analysis: Washington, DC, USA, 2017.

14. NHTS Administration. Traffic Safety Facts 2017 A Compilation of Motor Vehicle Crash Data; Report No. DOT HS 812 806; National Highway Traffic Safety Administration's National Center for Statistics and Analysis: Washington, DC, USA, 2019.

15. Florida Department of Highway Safety and Motor Vehicles. The Official Florida Driver License Handbook; Florida Department of Highway Safety and Motor Vehicles: Tallahassee, FL, USA, 2018. Available online: https:/ /www3.flhsmv.gov/handbooks / englishdriverhandbook.pdf (accessed on 19 June 2020).

16. Georgia Department of Driver Services. 2018-2019 Drivers Manual; Georgia Department of Driver Services: Conyers, GA, USA, 2018. Available online: http:/ / www.eregulations.com/wp-content/uploads/2018/07/18GADM-LR.pdf (accessed on 19 June 2020).

17. State of California Department of Motor Vehicles. Preparing for Your Driving Test (FFDL 22); State of California Department of Motor Vehicles: Sacramento, CA, USA, 2017. Available online: https://www.dmv.ca.gov/portal/dmv/detail/pubs/brochures/ fast_facts/ffdl22 (accessed on 19 June 2020).

18. Texas Department of Public Safety. Texas Driver Handbook; Texas Department of Public Safety: Austin, TX, USA, 2017. Available online: https: / / www.dps.texas.gov/internetforms /Forms/DL-7.pdf (accessed on 19 June 2020).

19. Mollenhauer, M.A.; Dingus, T.A.; Carney, C.; Hankey, J.M.; Jahns, S. Anti-lock brake systems: An assessment of training on driver effectiveness. Accid. Anal. Prev. 1997, 29, 97-108. [CrossRef]

20. Petersen, A.; Barrett, R.; Morrison, S. Driver-training and emergency brake performance in cars with antilock braking systems. Saf. Sci. 2006, 44, 905-917. [CrossRef]

21. Mims, L.; Brooks, J.O.; Jenkins, C.; Stronczek, A.; Isley, D.; Gubitosa, D. Teenage and Adult Drivers' Views of a One-Day Car Control Class on a Closed-Road Course. Safety 2020, 6, 57. [CrossRef] 
22. Ohland, M.W.; Loughry, M.L.; Woehr, D.J.; Bullard, L.G.; Felder, R.M.; Finelli, C.J.; Layton, R.A.; Pomeranz, H.R.; Schmucker, D.G. The comprehensive assessment of team member effectiveness: Development of a behaviorally anchored rating scale for self-and peer evaluation. Acad. Manag. Learn. Educ. 2012, 11, 609-630. [CrossRef]

23. Williams, A.F.; Wells, J.K. Driver experience with antilock brake systems. Accid. Anal. Prev. 1994, 26, 807-811. [CrossRef]

24. Mims, L.; Brooks, J.O.; Jenkins, C.; Schwambach, B.; Gubitosa, D. Teenage Drivers' Views of a Classroom and Closed-Road Post-License Advanced Driving Program, Guard Your Life. Safety 2020, 6, 44. [CrossRef]

25. Mims, L.; Brooks, J.O.; Jenkins, C.; Schwambach, B.; Gubitosa, D. Parents' Views of a Classroom and Closed-Road Post-License Driving Program for Teen Drivers, Guard Your Life. Safety 2020, 6, 56. [CrossRef]

26. Forkenbrock, G.J.; Flick, M.; Garrott, W.R. NHTSA Light Vehicle Antilock Brake System Research Program Task 4: A Test Track Study of Light Vehicle ABS Performance Over a Broad Range of Surfaces and Maneuvers; Report No. DOT HS 808 875; National Highway Traffic Safety Administration: Washington, DC, USA, 1999.

27. Koppa, R.J. Human Factors. Human Factors In Monograph on Traffic Flow Theory; Federal Highway Administration Research and Technology: Washington, DC, USA, 1997. Available online: https://www.fhwa.dot.gov/publications/research/operations/tft/ (accessed on 12 June 2021).

28. Brooks, J.; Kellett, J.; Seeanner, J.; Jenkins, C.; Buchanan, C.; Kinsman, A.; Kelly, D.; Pierce, S. Training the motor aspects of pre-driving skills of young adults with and without autism spectrum disorder. J. Autism Dev. Disord. 2016, 46, $2408-2426$. [CrossRef] [PubMed]

29. Brooks, J.; Seeanner, J.; Hennessy, S.; Manganelli, J.; Crisler, M.; Rosopa, P.; Jenkins, C.; Anderson, M.; Drouin, N.; Belle, L.; et al. Interactive tools for measuring visual scanning performance and reaction time. Am. J. Occup. Ther. 2017, 71, 710235001020102350020. [CrossRef] [PubMed] 